\title{
GLÓRIA MARIA SANTOS PEREIRA LIMA (1946-2017)
}

Formada em psicologia, Glória iniciou suas atividades na Fundação Carlos Chagas em meados da década de 70, aí encontrando um espaço propício à realização de seus projetos.

$\mathrm{Na}$ instituição, chefiou o Departamento de Testes e Medidas por mais de 20 anos, onde desenvolveu um minucioso trabalho voltado para processos seletivos de diferentes naturezas, bem como para avaliação de sistemas e de programas no campo educacional, experiência pela qual foi convidada a compor o Comitê Editorial da revista Estudos em Avaliação Educacional.

Desde 2007, integrou a Diretoria da Fundação Carlos Chagas, primeiro como Diretora Secretária-Geral, depois como Vice-Diretora e, mais recentemente, como Diretora-Presidente, atuando para a manutenção da sólida reputação dessa instituição, tanto na área de pesquisa educacional como na de seleção de recursos humanos.

Aqueles que tiveram o privilégio de compartir de seu convívio destacam sua competência e seu senso de humor particular. Dona de uma personalidade despojada, sempre que alguém precisava conversar com ela dispensava as 
formalidades inerentes aos cargos ocupados e oferecia o seu sorriso convidativo, disposta a partilhar seus conhecimentos e a interagir com seus colegas desprendidamente.

Os depoimentos aqui recolhidos registram não apenas saudades e lembranças, que compartilhamos com seus amigos e familiares, mas atestam também o compromisso e a diligência com que Glória pautou suas atividades nesses 40 anos de trabalho dedicados à Fundação Carlos Chagas.

RUBENS MURILLO MARQUES

Presidente de Honra da Fundação Carlos Chagas

\section{NOSSA AMIGA}

Você acha impossível a irreverência e o desbocamento conviverem com um alto senso de entrega profissional? Acha difícil que, de um posto de comando, emanem ao mesmo tempo alguns deboches e acertadas decisões? Não acredita que o melhor do humor possa se aliar a um profundo senso de justiça? Você não admite um espírito satírico que seja capaz de concentrar-se numa tensão de alta voltagem poética? Acha que um humor esparramado e aberto não permite um foco preciso e sensível ao ponderar uma questão problemática? Você não conheceu a Glória!

Viemos nos conhecendo ao longo de 40 anos. Quando ela era psicometrista, eu corrigia redações na Fundação Carlos Chagas, ainda entre poucas conversas. Com o tempo, ela foi assumindo outras funções e me convocando para elaborar provas. Aprendi a tornar concisa a redação de um enunciado, formular alternativas condizentes com uma raiz, escolher o que importa para uma objetiva cobrança de conteúdo. Mas, para muito além dessas contribuições "técnicas", ela me estendeu sua amizade - o que significou desfrutar, em tantos momentos, de sua personalidade estonteantemente rica. A intensidade da vida, para ela, como para os autênticos humanistas, era tudo e era pouco. No exercício desse paradoxo de fundo, havia espaço para os dotes raros da atenção generosa devotada a cada pessoa, atenção justa, jamais complacente ou evasiva. A dureza eventual de um 
juízo era também, no limite, prova de respeito pelo trabalho e pelo outro, excetuando algum caso de má-fé, que nunca lhe escapava e que ela não admitia.

Conversar com ela era ir surpreendendo, no rosto e nos timbres da voz, uma variada sucessão de humores e de pontos de vista, podendo alternar-se a objetividade de uma ponderação sisuda com uma careta de ironia. Nada inconsequente: tudo nela tinha de corresponder a um fundo da verdade sua, estivesse esta onde estivesse. Sua liderança dispensava o autoritarismo porque investida da autoridade que conta, quando ética, competência, decisão e largueza humana se compõem sem esforço. Mesmo o sotaque interiorano era por vezes forçado até à caricatura, para relaxar o interlocutor, quando não era uma espécie de vingança contra as inflexões impessoais das pessoas empoladas.

Perdê-la para o convívio é uma brutalidade, mas nada elimina dos ganhos que ficaram. Cada um de seus amigos, cada uma de suas amigas sabe do que falo: ninguém terá dúvida quanto ao que dela é legado ativo. Tento formular a importância afetiva que ela assumiu para mim, e esbarro na dificuldade de explicar o quanto conversar com ela constituía um exercício de crítica libertária, um confronto afetuoso de humores, um espaço franco e original onde até os nossos defeitos tinham algo de virtuoso - e junto com tudo isso talvez uma melancolia disfarçada, quase imperceptível, rápida sombra, lastro inevitável de sua profunda humanidade.

Nada mais justo que uma personalidade dessas assumisse o posto mais alto da instituição onde viveu boa parte de sua vida: não é sempre que se reconhece a extensão de um mérito. Maior que tudo, no entanto, será a pessoa que ficou entre nós, a ser festejada pela singularidade humana que conquistou para si e distribuiu para todos. 
Novos contornos nítidos no espaço:

teu corpo

teu rosto

teu humor teu espalhafato

tua palavra aguda

teu olhar de frente

teu amor

teus pãezinhos de Santo Antônio

tua Falta

ALCIDES VILLAÇA

Faculdade de Filosofia, Letras e Ciências Humanas da Universidade de São Paulo, São Paulo-SP, Brasil

Mais uma perda com que aprendemos a conviver.

A vida nos traz ensinamentos e com eles vamos revisitando aquilo que realmente é importante. Como minha religião acredita que estamos somente separados em viagem, ainda acredito que nos encontraremos e faremos muitas provas juntos em outro plano.

Deus nos dará força aqui para darmos conta de nossas vidas e a Glória agora nos ajudará como um anjo a nos orientar a fazer as melhores escolhas.

Pessoa especial e exemplo de mulher e profissional. Extremamente generosa em seu saber e principalmente humana em seu reconhecer.

Obrigado por tudo que fez e ainda fará por nós.

Saudades.

AGNELSON RICARDO CORREALI

Colaborador da Fundação Carlos Chagas

Glória. lembranças mil. líder estudantil em Campinas, agitada, firme, doce, bem formada, prolongou sua atuação em São Paulo e levou seu modo de ser dinâmico para o trabalho. Fez de sua casa lugar de reuniões e de consolidação de propostas de ações, revistas, textos diversos. Competente, 
exigente, perspicaz, parceira e companheira, realizou seu percurso profissional na Fundação Carlos Chagas chegando à Presidência da instituição, sempre com um cumprimento caloroso, um sorriso e sua risada retumbante, sempre ajudando e formando, mas não temendo tomar decisões, às vezes muito difíceis. Tive o gosto de compartilhar décadas de trabalho com ela, discutindo as questões da pesquisa e aprendendo sobre avaliação e testes de desempenho educacional. Já parceira no trabalho, foi minha aluna no mestrado em Psicologia da Educação na PUC-SP e, durante o curso, não só debatemos conhecimentos mas também comemos muitos pastéis (era o dia da feira e ambas adorávamos pastéis!). Quantas trocas e quanto apoio da parte dela em relação às ideias que ousávamos nas pesquisas. Saudade é o que fica.

BERNARDETE A. GATTI

Consultora da Fundação Carlos Chagas e Presidente do Conselho Estadual de Educação de São Paulo, São Paulo-SP, Brasil

Sou, em grande medida, como costumo dizer, "cria” de Glória e Lígia, que, cada qual a seu modo, me iniciaram e conduziram pelos caminhos da Fundação. Tive, tenho e sempre terei muito carinho por ambas, e ter podido homenagear uma e abraçar a outra, estando em meio a vocês, deu-me um sentido de pertença e continuidade, segurança e certeza de estar entre pessoas responsáveis e, acima de tudo, queridas. A vocês, muito obrigada.

CHRISTIANNE BOULOS

Colaboradora da Fundação Carlos Chagas e mestre

e doutora em Direito do Estado pela Faculdade de Direito da Universidade de São Paulo, São Paulo-SP, Brasil

\section{GLÓRIA LIMA - GESTORA COMPETENTE E AMIGA}

Sinto-me lisonjeada e orgulhosa de poder apresentar também minha visão de como Glória Lima afetou nossas vidas na FCC e fora dela. Continuando a obra de pioneiros no tema 
na FCC, como o Prof. Heraldo Vianna, Glória soube ir além e fazer de sua herança um grande legado.

A construção de um setor de testes e medidas que apresenta hoje um reconhecimento nacional exigiu de Glória muita dedicação. Assinalo aqui alguns pontos.

- Em primeiro lugar ela tinha claro que era preciso apostar na sabedoria do fazer boas medidas, boas provas para conduzir processos seletivos que primassem pela excelência e pela qualidade técnica. Saber construir uma prova não é uma competência que se adquire somente com o conhecimento sobre medidas educacionais, mas exige perspicácia e profundo conhecimento dos problemas que envolvem os elaboradores de provas, suas dificuldades e seus erros mais frequentes. Aspectos esses que eram compreendidos e dominados com maestria por Glória. Com sua clareza de raciocínio conseguia identificar problemas tão sutis de uma prova, mesmo depois de ter sido analisada por inúmeros corretores, que me deixava sempre admirada. Sua criticidade, sobretudo nas provas das áreas de direito e saúde, era ainda mais admirável.

- Mas o trabalho de construção de provas de concursos comporta também outras exigências. É preciso promover o sigilo, e Glória, zelosa desse sigilo, cuidou para que seu grupo o entendesse como um valor a ser preservado entre todos. Instituiu uma aura a esse respeito. Parecia mesmo que todos ali, em seu grupo, guardavam um segredo sobre o qual não falavam na presença de estranhos e sobre o qual somente se podia comentar cuidadosamente com os iniciados e aqueles cuidadores desse segredo. Surtiu efeito, sem dúvida. Nunca houve vazamentos, vendas ou desvendamento involuntários dos segredos das provas.

O desenvolvimento de todo esse nível técnico adquirido pelas provas elaboradas em seu setor exigia a construção de amizades sólidas, de fidelidades e da seleção de pessoal competente. Nesse aspecto não havia dúvida, seu grupo era sua 
referência, e sua dedicação a ele sempre foi inquestionável. Sabia e sempre soube que a construção da qualidade técnica exige tempo, atenção, cuidado, muito estudo e experiência. Acompanhava de perto a construção da renovação de seu grupo, apontava caminhos e, de forma cuidadosa, corrigia os escorregões para assim garantir o nível de qualidade técnica desejado. Todos sabiam que ganhariam muito ouvindo sua palavra final, sua análise aguda sobre um determinado assunto, sobre um projeto e sobre uma prova.

Guindada por circunstâncias e reconhecimento a postos mais altos na própria FCC, sua preocupação com o desenvolvimento da Instituição sempre esteve à frente até de sua saúde, de seu cansaço e do cuidado consigo própria. Mas foi ali também que mostrou seu jeito de governar com o coração, com acolhimento e com atenção extrema a cada pormenor. Nunca manteve portas fechadas. Nunca se negou a conversar. Com escuta sempre atenta, tinha claro conhecimento do que se passava na FCC e sabia, e como sabia, esperar o momento, a ocasião para apresentar sua sugestão, sua opinião. Muitos diziam e pediam para ela se apressar, para indicar mais, para falar mais, mas sabiamente tinha aprendido, com sua experiência na FCC, qual era o tempo que essa organização precisava para ter ouvidos capazes de ouvir e para aceitar o que seria dito.

Se ela fará falta? Claro que sim. Já está fazendo. Teria tanta coisa a dizer e gostaria tanto de escutar sua opinião!

Receba um grande abraço, amiga querida.

CLARILZA PRADO DE SOUSA

Consultora da Fundação Carlos Chagas e professora da Pontifícia Universidade Católica de São Paulo, São Paulo-SP, Brasil

Conheci Glória assim que entrei na FCC, em 1978, como bolsista de pesquisa. O Departamento de Pesquisas Educacionais - DPE - era formado, à época, por um grupo de pesquisadores que mantinha diferentes posições a respeito das prioridades do país, não só quanto à Educação como quanto a outros temas emergentes, como gênero e raça/etnia. Esse 
clima, se rico de ideias e de desafios, não deixava de ser intimidante, em especial porque existiam disputas e conflitos que se manifestavam em acirradas discussões. Para uma novata no mundo acadêmico que ignorava ser essa a norma, eu me encolhia, evitava me expor, tentava "preservar a face", como hoje se diz. Foi, portanto, uma feliz surpresa conhecer Glória, que chefiava o Departamento de Testes e Medidas - DTM -, situado em outro prédio da FCC. A primeira vez que a vi, tive certeza de que estava diante de uma mulher forte, vital, alguém que gostava de gente, de viver bem e do que fazia. Pouco interagíamos naqueles tempos, embora fosse impossível não perceber, pela fala alta, descontraída, afável, quando ela pisava no DPE, quebrando sua sisudez e silêncio.

Foi só em 1981, em um projeto chamado Edurural, que ficamos mais próximas. Era preciso elaborar uma prova a ser aplicada a alunos e professores que atuavam na zona rural do nordeste do país, e fomos pedir o auxílio de Glória. Passamos a noite elaborando questões juntas, como se fôssemos um time. Sua incrível capacidade de identificar conteúdos centrais, estabelecer relações entre eles, propor itens e sugestões de resposta, rever e sugerir alternativas melhores era fascinante. Ficava espantada por ver alguém que - formada, como nós, em psicologia, e apenas alguns anos mais velha dominava tanto conhecimento pedagógico e técnico, tantas leis e normas jurídicas. Trabalhávamos duro, mas também contentes e nos divertindo, porque ela era muito engraçada, troçava de si mesma e de algumas de nossas mirabolantes ideias, fazia-nos rir. Tudo isso criou entre ela e nós, bolsistas, um laço sólido de respeito, amizade e companheirismo.

Todas nós a admirávamos por sua audácia e autonomia. Quando foi proibido fumar nas dependências da FCC, Glória, depois do expediente, horário em que mais nos encontrávamos para trabalhar, no que a mim parecia ser um ato de bravura, tirava da bolsa um cigarro e o acendia sem hesitação. Nesses momentos, ela comprava sanduíches de mortadela para matarmos a fome e, ainda, bolinhos com cremes para adoçar a vida. Reunidas em volta da mesa para 'jantarmos', ela desviava a conversa de questões relativas ao trabalho. Falávamos de tudo um pouco: de política, filhos, culpas, 
medos, ressentimentos, projetos e anseios. Nós ouvíamos com prazer seu vozeirão, sua ironia fina, seu bom humor que apagava o cansaço. Sua disposição era inspiradora: tudo o que era maçante virava festa com ela. Vou ficar para sempre com o seu "né, bem?" e "lindinha, me faz um favor?".

Nos vários postos que ocupou na FCC, Glória sempre manteve uma incansável dedicação, algo que não a deixava agir sem que tivesse serenidade e segurança. Permaneceu sempre a mesma pessoa: as posições de maior poder não lhe retiraram a amabilidade, a gentileza e nem a alegria. Certamente, foram muitas as preocupações e turbulências que enfrentou, mas Glória sempre agiu com firmeza, espalhando entre nós, com a vitalidade que lhe era própria, confiança e tranquilidade em muitos momentos difíceis. Seu estilo de liderança fazia-nos acreditar que sua carga, se sabidamente pesada, era algo passageiro e que logo se iria. Facilitou essa tarefa sua habilidade em mediar conflitos e sua perspicácia em entender o ponto de vista do outro.

Nas relações interpessoais, Glória usava suas artimanhas: quando não queria discutir algo, ela nos enrolava com uma fala coerente, mas absolutamente ininteligível, de modo que, ao final do encontro, saíamos sem saber ao certo qual era sua opinião ou o que ela esperava que fizéssemos. Era sua maneira de não nos deixar sem respostas e, também, de ganhar tempo para refletir melhor sobre o assunto. Por vezes, suas análises eram tão argutas que chegamos a crer que ela era uma maga poderosa e clarividente, que contava, ainda por cima, com a cumplicidade dos deuses.

Quando adoeceu, a gravidade de seu estado não a abalou. Vinha trabalhar, mesmo tendo acabado de sair do hospital. Quando a visitamos depois de uma cirurgia, nós a encontramos impecável em seu quarto, de colar e brinco, batom na boca, cabelos arrumados. Não perdia a pose e nunca, nem nos piores períodos, a alegria e o bom humor. No momento, pensar nela dói muito. Mas, quando a tristeza for embora, seu espaço será preenchido por ótimas memórias. Só lamento não ter gravado sua risada alta, vibrante e sonora, que fazia com que esquecêssemos o ardido da vida e nos empurrava para frente. 


\section{GLÓRIA PEREIRA LIMA IN MEMORIAM}

Foi ao largo da longa trajetória profissional que Glória Pereira Lima percorreu na FCC, iniciada há 40 anos na área da psicometria, que ela adquiriu a expertise que a tornou uma das pessoas chave no campo da avaliação, em que a instituição é tida como entidade de referência.

O trato com as metodologias avançadas e as tecnologias de ponta, adotadas desde então, proporcionou-lhe o domínio teórico-prático necessário à realização dos testes e medidas que passam pelos exames vestibulares, pelas avaliações de sistema, por avaliações da aprendizagem e de programas, dentre outras, assim como pelos concursos de seleção de profissionais para entidades públicas e privadas. Glória também dominou com mestria as complexas formas de operacionalização da aplicação das avaliações em larga escala e da apuração e análise dos resultados obtidos, tendo ainda desenvolvido e incentivado estudos para aquilatar a sua efetividade e impactos.

Em todas as etapas dos processos avaliativos, ela imprimia a marca da competência na sua condução, a garantia da qualidade irretorquível das tarefas executadas, a ética e a transparência nos seus diferentes passos. Mas ela também sempre se preocupou com a relevância social das ações de avaliação em termos do alcance que podiam ter para a democratização da educação, e para a justeza e propriedade dos processos de seleção de profissionais dos mais variados campos de atividade. Estava certa de que as políticas de avaliação dos sistemas educacionais tinham condições de contribuir para assegurar aos estudantes, às famílias e à sociedade o direito de exigir dos órgãos públicos melhorias na qualidade do ensino. Por isso julgava que extinguir essas avaliações seria fraudar um direito legítimo da população.

Foi assim que Glória chefiou o Departamento de Testes e Medidas por muitos anos na FCC, sempre atenta à formação e ao aperfeiçoamento constante dos profissionais que com ela atuavam, e sempre sensível às dimensões humanas das relações de trabalho que aí se estabeleciam.

Também não lhe faltaram o interesse e os esforços para intensificar o entrosamento das atividades de avaliação com as atividades do Departamento de Pesquisas Educacionais, 
que tanto têm contribuído para o prestígio de que goza a instituição no campo acadêmico e da gestão das políticas públicas.

Imbuída desse espírito é que passou a fazer parte da diretoria da FCC em 2007, assumiu o cargo de diretora vice-presidente em 2013, e tornou-se diretora-presidente da Fundação no ano seguinte.

A grave enfermidade que a vitimou, e que ela insistia em considerar como um "desvio de percurso", não a deixou abater-se; manteve-se firme e determinada na condução da instituição, com lealdade aos seus propósitos primeiros. Nunca abdicou de passar a todos que com ela conviviam a alegria, a coragem e a energia necessárias para prosseguir em frente naquilo que acreditava que valia a pena.

Ao se extinguirem suas forças, ela certamente poderia ter falado como Manuel Bandeira, em "Consoada":

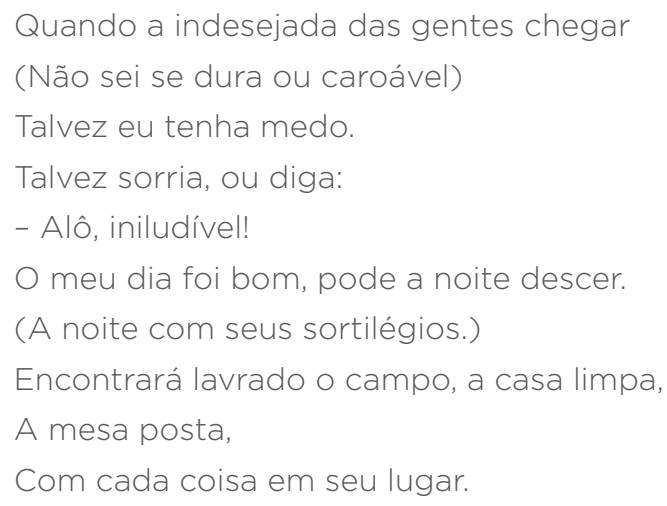

ELBA SIQUEIRA DE SÁ BARRETTO Consultora da Fundação Carlos Chagas e professora da Faculdade de Educação da Universidade de São Paulo, São Paulo-SP, Brasil

\section{MINHA AMIGA GLÓRIA}

Sou amiga da Glória desde 1958. Tínhamos 12 e 13 anos, respectivamente. Estudávamos no curso ginasial do Instituto de Educação Estadual "Carlos Gomes", em Campinas. A escola estava começando a adotar algumas alternativas propostas pelo grupo da chamada Escola Nova, identificados com o famoso Manifesto. A escola ganhou uma orientadora educacional cheia de propostas inovadoras e avançadas para 
uma escola tradicional - a professora Angélica. Tínhamos aulas de Educação Sexual e podíamos não assistir às aulas de religião. Elegíamos nossos representantes de sala para avaliar o projeto da escola e a qualidade das aulas ministradas. Nascia a participação estudantil estimulada pelas direções da própria escola. Participávamos do Grêmio Estudantil Castro Alves e, depois, da Associação Normalista "Álvares de Azevedo". Eu, por conviç̧ão; ela, por solidariedade, mas exercia muita liderança. Fazíamos teatro. Criamos um clube (de amigos): o Negadinha's Club. Líamos J.P. Sartre (no original, em francês), e, mesmo não entendendo quase nada da obra L'Être et le néant, citávamos frases de efeito, pois era moda ser "existencialista", andar de preto e ter um ar misterioso...

Semanalmente tomávamos sorvete na Torre de Pisa - a melhor da cidade, e sempre apostávamos se conseguiríamos comer o maior sorvete (a banana split) e um ice cream soda, um após o outro... Depois íamos ouvir rock. Vitrolas com som estereofônico haviam acabado de chegar no mercado e o som era muito melhor que os anteriores. Elvis Presley era nosso preferido. Mas, às vezes, para variar, Pat Boone também. Roberto, Wanderleia e Erasmo Carlos estavam aparecendo e... chocando! "Subi a rua Augusta a 120 por hora..."

Como ela morava em Sousas - na época, um distante distrito de Campinas, hoje incorporado à cidade -, ela dormia em casa com frequência, pois o último ônibus saía às $20 \mathrm{~h}$ e a conversa rolava até a madrugada... Ríamos muito juntas, inventando histórias.

No início dos anos de 1960, a Teologia da Libertação era referência para as novas concepções da Igreja Católica e os padres e freiras que nela acreditavam buscavam formar lideranças jovens, com o objetivo de propor a transformação social, por meio de um projeto de sociedade menos desigual. Fomos escolhidas e atuamos no movimento estudantil secundarista lideradas por essa conviç̧ão. Estudamos juntas até nos formarmos no Curso Normal. Depois, já professoras, tomamos rumos diferentes: eu fui fazer Pedagogia, em 1963, e ela, Psicologia, em 1964.

Reencontramo-nos quando ela e o Marco Aurélio (Lelo) resolveram se casar. Já estávamos, ambas, morando em São Paulo. Eu fazia pós-graduação em Ciências Sociais, na 
USP; ela já discutia a importância de medidas educacionais e de aprendizagem. Estávamos em 1968. E nunca mais nos separamos... Eu já havia ido trabalhar em Alagoas e ela dava aulas em São Paulo, em escolas públicas e privadas. E, em função de sua atuação competente e inovadora, quando trabalhava como professora alfabetizadora numa escola judaica da elite econômica paulista, foi convidada a visitar Israel e conhecer a experiência inovadora, na época, dos Kibutz...

Depois, resolveu ir trabalhar na Fundação Carlos Chagas, no Departamento de Testes e Medidas. Ali conheceu o prof. Heraldo M. Vianna, seu chefe e amigo, e já no final dos anos 70, adotou-o como intelectual preferido e orientador das suas questões e dúvidas sobre seleção de pessoal, elaboração de testes e análise do desempenho dos participantes, em variadas profissões. E de lá não saiu mais...

Glória Maria Santos Pereira Lima dedicou toda sua vida profissional à Fundação Carlos Chagas. Mantinha com ela uma espécie de relação simbiótica, fazia críticas, mas não podia viver sem ela. Competente, acolhedora e criteriosa. Honesta e ética, chegava a ser humilde por conviç̧ão. Possuía um excelente currículo construído na competência prática e na formação teórica consistente. Nunca quis se "titular" do ponto de vista acadêmico. Sabia tudo sobre a TRI, suas vantagens e limitações. E alertava sobre isso, o que incomodava alguns especialistas da área de avaliação educacional. Ajudou muitos(as) a se tornarem "doutores(as)": leu suas teses, fez sugestões, corrigiu algumas... era uma espécie de coorientadora disponível. Poucos a agradeceram como merecia. Mas ela não se importava. Preocupava-se que os processos de seleção de pessoas da FCC e as teorias sobre eles traduzissem efetivamente critérios rigorosos de mérito profissional. Cumpriu bem seu papel. Foi um belo exemplo para todos(as). É difícil substituí-la. Que saudades da Glória!

LISETE REGINA GOMES ARELARO

Faculdade de Educação da Universidade de São Paulo, São Paulo-SP, Brasil 
Glória,

como é difícil falar agora com você, estando você tão longe que eu não percebo sua voz, nem mesmo a alegria de sua inconfundível risada!

Sei, porém, que você deverá estar me ouvindo, na amplidão sideral em que certamente agora se encontra, porque falo de um longo tempo de convivência, de afeto e respeito mútuos, de muito trabalho, bom, gostoso e, especialmente, produtivo.

Lembra-se de que planejamos prova até em uma passagem de ano? Pois para você não havia tempo ruim, não havia prazos mínimos, nem mesmo prazo nenhum, não é? A prioridade estava na realização do melhor trabalho, a tempo, ainda que surgissem obstáculos, que você sabia sempre como superar.

Mas, acima de tudo, Glória, havia seu senso de responsabilidade, havia seu exemplo de retidão moral, de coragem para enfrentar desafios, de levar avante os compromissos assumidos - em suma, o exemplo que você deixa, de pleno envolvimento com o nome e com o cumprimento dos objetivos que norteiam as atividades da Fundação Carlos Chagas.

Foram muitos anos, Glória. Foi um bom tempo, que agora se encerrou para você. Restaram inúmeras boas lembranças de todo esse período, e agora permanece apenas a saudade. Fico pensando, de um modo bem egoísta, que você partiu cedo, deixando-nos um vazio, um doloroso silêncio, um imenso sentimento de perda.

Seu descanso, porém, é mais do que merecido; você cumpriu com garbo sua missão.

Adeus. Descanse em paz, Glória.

MAGDA MARTINS FALCO

Colaboradora da Fundação Carlos Chagas

\section{GLÓRIA}

Mulher de personalidade forte, espontânea e cativante. Creio que essa é a maneira como Glória será lembrada por todos nós. Da minha convivência diária, posso dizer que Glória foi mãe, foi amiga, foi conselheira e principalmente uma chefe-guia. Sabia a hora exata de soltar uma gargalhada, inconfundível, no meio de 
uma reunião tensa e abrandar o clima com um belo sorriso no rosto. Nada para ela era problema: “É assim e ponto!”. Quando sugeria algo que ela não se sentia confortável em concordar ou deliberar favoravelmente, para que não me percebesse desmotivada, de maneira polida respondia com um "Vou pensar!".

A convivência foi uma grande faculdade. Aprendi a acreditar, ainda mais, na força das palavras. Creio que por isso Glória soava seu mantra dizendo que "tem uma doença, mas não estou doente!". Transmitia-nos uma imagem altiva, positiva e alegre, sabia que agindo dessa forma ela nos tranquilizava e, consequentemente, a energia a sua volta era positiva, "SEMPRE!".

Glória me ofereceu cuidado, carinho, proteção e me assistiu nos momentos mais importantes da minha vida nos últimos anos. Esses gestos jamais serão esquecidos, sou eternamente grata a Deus e à Glória por tê-la em minha vida. Daqui para frente sigo a caminhada com seus ensinamentos, sem ela ao lado fisicamente, mas ouvindo a todo momento sua voz marcante soprando em meu ouvido um "olha lá, hein, menina!".

MARIA HELENA BOTTURA

Ex-Coordenadora do Departamento Administrativo da Fundação Carlos Chagas

Todos nós temos uma professora que representou algo especial em nossa trajetória escolar. Eu tive a professora do $2^{\circ}$ ano primário. Só não sabia que depois de terminar o ensino superior, trabalhando profissionalmente, encontraria a maior de todas as professoras, Glória.

E pelas mãos dela o rumo da minha vida mudou. Aprender e apreender o ofício, a perspectiva da Educação. E assim fomos construindo uma história e o trabalho. Como ela falava: - "Ô, minha trintaano!".

Tarefa difícil descrever tudo isso que vivemos, dias tensos, dias intensos e dias de calmaria, o barco deslizava em águas tranquilas, e ela no comando do leme. Olhares, caras, caretas, gargalhadas, a inteligência, a voz...

A sua sala sempre de portas abertas para todos. Havia uma palavra, uma graça e até mesmo um papo sério, 
respeitador, conselheiro e aconchegante... e ela vibrava com as conquistas profissionais e pessoais.

Ensinou tudo o que sei sobre esse ofício. Mostrou os caminhos e plantou o respeito pelos envolvidos em cada projeto, em cada canto da vida. A seriedade, a condução, a ética e o bom humor.

Parte e reparte o pão. Com manteiga é muito bom. Os meninos Guso e Rica correndo entre nossas mesas, e o tempo passando, passado. Hoje orgulho da Mãe. Afinal, criançada, prestenção. E essa fala para muitos, jeito Glória de ser, único.

Obrigada, Glória, por existir em minha vida!!!

Em mim, sempre... e Saudade!!!

Isabol

MARIA ISABEL VILLA RIOS LOPEZ

Psicometrista da Fundação Carlos Chagas

O que tenho para falar de uma pessoa como minha amiga Glória? Acho que tudo o que seus amigos também irão dizer. Portanto, não pretendo ser original e sim mais uma a testemunhar o que ela sempre foi: uma mulher forte, corajosa e admirável.

Conheci a Glória já trabalhando na Fundação Carlos Chagas, quando juntas desenvolvemos um projeto sobre avaliação e, ao longo desses 22 anos de convívio, construímos uma grande e profunda amizade.

Nessa jornada, tive a oportunidade de conhecer uma pessoa generosa, companheira e paciente, que se tornou uma boa ouvinte e conselheira. Muito equilibrada, mesmo nos momentos mais dificeis, nunca perdeu a objetividade nem o bom humor.

Ela foi para mim uma grande professora da vida e me fez uma pessoa melhor.

O que resta agora é a dor da perda de uma companheira de vida, mas sei, como todos seus amigos sabem, que ela amava viver e que gostaria que continuássemos com a mesma alegria que ela tanto fez por semear. O que fica agora é a saudade. 
Como era bom encontrar Glória pelos corredores da Fundação, quando, com apenas um sorriso maroto, algumas brincadeiras, certas pitadas de ironia, ela reafirmava uma proximidade amiga, a despeito dos diferentes departamentos, diversos afazeres e distintas áreas de trabalho. Há algumas décadas havíamos participado de precoces tentativas de organizar mobilizações pelo direito à educação, durante o início da chamada transição democrática. Foi a época em que as reuniões anuais da SBPC, as Conferências Brasileiras de Educação, as reuniões da ANDE e da ANPEd eram ocasiões de somar forças nos movimentos pela democratização da educação. Glória também tomava parte desse processo e essas memórias comuns talvez tenham facilitado nossa aproximação, mesmo que por breves momentos, ao longo dos anos. Como todo mundo, sentirei sua falta nos encontros fortuitos, mas sempre calorosos, roubados de seu sempre intenso ritmo de trabalho.

MARIA MALTA CAMPOS

Consultora da Fundação Carlos Chagas e presidente da ONG Ação Educativa, São Paulo-SP, Brasil

\section{FRAGMENTOS DE UMA GRANDE AMIZADE}

Mexer e remexer o baú de memórias afetivas não é das tarefas mais fáceis. Especialmente, quando elas se referem a uma amiga de mais de cinco décadas. São muitas e muitas histórias. E é evidente que se corre o risco de não selecionar as melhores ou as mais interessantes. Mas, vamos lá!

Pouco mais que uma adolescente, Glória liderava um movimento de jovens e, como tal, tornou-se conhecida em Campinas e no pequeno distrito de Sousas, em que morava. Sua capacidade de argumentação, perspicácia e agilidade de raciocínio somada à grande afetividade com que tratava as pessoas fizeram dela uma referência para jovens da região e de outras localidades. Naquela época, sem internet, sem celular e sem DDD, a comunicação era feita por correspondência. Cartas endereçadas a ela chegavam sem seu endereço e nome completo. Alguns, apenas subscritos com: Glória, 
Sousas - São Paulo. Para nosso espanto, as cartas eram entregues corretamente. Certa vez, perguntei intrigada ao carteiro da região como sabia que as cartas eram para ela, e ouvi a seguinte resposta: "Mas é claro que sei! Ela é a pessoa mais famosa daqui! Sentimo-nos orgulhosos e agradecidos! Graças à Glória, o Brasil sabe que Sousas existe!”.

Antes de sua trajetória pela FCC, trabalhamos juntas em uma instituição educacional israelita, laica, em São Paulo. Jovens, curiosas, logo aprendemos parte da cultura judaica, de sua gastronomia e do significado de suas festas. Do vocabulário hebraico, sabíamos mais que shalom, pessach e shabat, além de algumas canções e orações. Animados, os dirigentes resolveram proporcionar aos educadores um curso de hebraico, sem obrigatoriedade de frequência. Lá, nos matriculamos. Na primeira aula, sala lotada! Mais de 30 participantes. A maioria de origem judaica, com relativo conhecimento da língua. Na segunda aula, somente metade dos inscritos. E, sucessivamente, as desistências foram aumentando. Entre elas, a minha. Do grupo original, Glória permaneceu até o curso ser extinto por falta de quorum. Exemplo de brava resistência ao desafio de aprender uma língua de raiz e sistema de escrita tão diversos! Por essa e por outras atitudes, era respeitadíssima na instituição, o que lhe valeu uma viagem de estudos a Israel. Contudo, essa não foi sua primeira experiência em relação à extinção de um curso de língua estrangeira. Antes, havia frequentado um curso livre de russo, na USP, até ser cancelado por evasão dos alunos. Nos últimos anos de sua vida, me dizia, em meio às gargalhadas: "Desisti de estudar grego! Faço italiano, sei mais que tutti buona gente, divirto-me muito e não corro o risco de ser suspenso!".

Glória nos transmitia segurança e, generosamente, dividia conosco sua força e sua coragem. Empurrava-nos para frente e nos encorajava. Lembro-me bem, há anos, no dia da defesa de meu mestrado. Sala lotada, na PUC de São Paulo: amigos, amigas, docentes e familiares. Minha voz, de início, baixa e trêmula, indicava a apreensão do que provavelmente viria pela frente. E, eis que, com alguns minutos de atraso, Glória entra na sala, me dá uma piscada, um 
sorriso rasgado e me faz o sinal de positivo com a mão. Daquele instante em diante, minha voz ganha corpo, o tom aumenta e a segurança se torna evidente. Aprovada com louvor! Na defesa de meu doutorado, também na PUC de São Paulo, eu lhe dizia: "Por favor, não chegue atrasada! Agora, a banca é maior!”. Na véspera, reforcei a questão do horário e lhe disse: "Se o resultado for bom, preparei uma festinha, em minha casa”. E ouvi dela um novo encorajamento: "A festa será realizada com qualquer resultado! Você chegou até aqui, já é vitoriosa!”. No dia, não só foi pontual como permaneceu na sala durante as mais de cinco horas de duração! Quando o resultado foi dado, idêntico ao anterior, foi minha vez de lhe piscar e de lhe sorrir, sinalizando a gostosa cumplicidade, que nos unia.

Em junho de 2015, um grande amigo nosso, morador de Manaus, faria aniversário. Sua esposa nos envia convite para a festa surpresa, com direito à missa solene, rezada pelo Bispo da cidade, recepção com música, telão com fotos de sua vida, entre outros preparativos. Nossas agendas estavam "apertadas", ela, na FCC, eu, em outra instituição. Nem pensei em ir. Cinco dias antes da festa, Glória me liga e diz: "Topas ir para Manaus? Faremos uma surpresa, um bate e volta, iremos sexta e voltamos sábado". Não vacilei e respondi: “Topo!". Coube a mim, correr atrás das passagens. Para retorno, no sábado, somente voo de madrugada, e preços altíssimos. Ficaríamos em Manaus, menos de 24 horas. Mas, nada impedia Glória de estar com os amigos, fosse na alegria, fosse na dor. Reservamos um hotel, para "nos escondermos" por algumas horas! Ao nos ver, nosso amigo dizia: "Não acredito! Vocês, aqui! Será que meu coração aguenta?". Não só aguentou, como desfilou todo orgulhoso com Glória, conhecida, não só pela FCC, mas por sua antiga liderança em Sousas. Em meio à festa, seu telefone toca. Era Ricardo, o filho mais novo, que havia chegado com uma amiga, em São Paulo, vindo de surpresa da Costa Rica, onde morava. Muito feliz e sem se abalar com o inesperado, ela lhe diz: "Daqui a pouco, estaremos aí". Ao desligar, dá uma gostosa gargalhada e me pergunta: "Com quem ele se parece?!”. 
Esses fragmentos me fizeram revisitar cenas em que percebo a impossibilidade de uma definição acabada de Glória, como amiga. Talvez, nem seja importante. Faltariam palavras para descrever tanta amorosidade, generosidade e coragem. A cena que me vem à memória é a de nosso brinde aos 50 anos de amizade com o prosecco, de que ela tanto gostava!

MARIA RITA APRILE

Pesquisadora da Fundação Carlos Chagas

\section{PSICO-MAESTRINA}

muito mais que 3+ longe da média

desvio padrão nenhum dava conta

validade de conteúdo geral ao profundo

precisão das palavras nas horas mais incertas

dava muitos nós nos traços latentes

seu escore bruto não diferia do verdadeiro

TRI-Clássica nas suas avaliações

a curva característica foi a grandeza da alma

das gargalhadas sonoras-largas das alegrias

à simplicidade do domínio de uma pletora de teorias

universo infinito de consistência interna

coeficiente Glória! Sempre! Eterna!

MARIA TERESA BARBOZA

Coordenadora do Departamento de Testes e Medidas da Fundação Carlos Chagas

Conheci Dona Glória há trinta anos e, desde então, passei a admirá-la, chegando logo a amizade e a estima recíprocas, que tanto me desvaneceram. Dotada de elevados atributos morais, neles despontavam a honestidade, a fidelidade aos princípios que elegeu, a dedicação ao trabalho, até seus últimos dias, a coerência e firmeza nas decisões que tomou, a lealdade aos amigos e às instituições, especialmente à Fundação Carlos Chagas, que foi a sua casa e à qual deu o 
melhor de si, vindo, por fim, a conduzi-la com maestria e denodo. Deixou-nos um legado de exemplos a serem seguidos e já é imensa a saudade.

NESTOR DUARTE Faculdade de Direito da Universidade de São Paulo, São Paulo-SP, Brasil
A notícia do falecimento da Glória me pegou de surpresa, trouxe um impacto forte, assim como as tempestades que atravessam os mares
e Glória, com seu brilho e alegria, inteligência viva e generosidade, bom humor e ousadia, integridade e força, atravessou a vida com energia criadora seu riso ainda ecoa em minha memória, e guardo com gratidão o privilégio de tê-la conhecido nesse momento de perda, eu me uno a tod@s vocês, num abraço fraterno e amoroso e peço a Deus que faça transbordar de paz e consolação o coração de todos os familiares e amigos da nossa queria Glória

NILCE EMY TOMITA Faculdade de Odontologia da Universidade de São Paulo, Bauru-SP, Brasil

Considerava Glória uma profissional de primeira linha, sempre disposta a apoiar e estimular o crescimento de todos os que estavam sob sua liderança. Além disso, era uma figura humana incrível, plena de alegria, companheira leal e disposta a defender com vigor e altruísmo os com ela envolvidos. 
É realmente uma pena que a vida tenha nos privado dela quando ainda teria tanto para dar.

\section{ROSE NEUBAUER}

Presidente da Câmara de Ensino Superior do Conselho Estadual de Educação de São Paulo e diretora presidente do Instituto Protagonistés, São Paulo-SP, Brasil

"Preciso que venha agora até a minha casa". Passamos a noite tecendo e remendando trabalho e vida. Essa é a Glória. Que Glória!

ZULEIKA DE FELICE MURRIE Doutora em Língua Portuguesa pela Universidade de São Paulo, São Paulo-SP, Brasil 